\title{
The Role and Prospects of Rare Earth Metals in the Development of Physical-Mechanical Characteristics and Applications of Deformable Aluminum Alloys
}

\author{
Jury A. Gorbunov \\ LLC "Research \& Development Center "SIAL" \\ 15a, Pogranichnikov Str., bld. 1, Krasnoyarsk, 660111, Russia
}

Received 21.05.2015, received in revised form 04.06.2015, accepted 21.07.2015

In the article the results of domestic development and application of aluminum alloys in the form of a rolled, extruded and forged semi-finished products as X-ray contrast materials, conductors, resistant to high temperatures, and structural materials of different destination.

Keywords: the state diagram of the aluminum-rare - earth metals, rapidly crystallized alloys with rare-earth metals, structure and physical and mechanical properties of semi-finished products from traditional systems of aluminum alloys with REM.

\section{Роль и перспективы редкоземельных металлов \\ в развитии физико-механических характеристик \\ и областей применения \\ деформируемых алюминиевых сплавов}

Ю.А. Горбунов

ООО «Инженерно-технологический центр «СИАЛ» Россия, 660111, Красноярск, ул. Пограничников, 15a, стр. 1

В статье рассмотрены результаты отечественных разработок и применения алюминиевых сплавов в виде катаных, экструдированных и штампованных полуфабрикатов в качестве ренгеноконтрастных материалов, проводников тока, стойких к воздействию высоких температур, и конструкиионных материалов различного назначения.

Ключевые слова: диаграмма состояния алюминий-РЗМ, быстро закристаллизованные сплавы с РЗМ, структура и физико-механические свойства полуфабрикатов из сплавов алюминия традиционных систем легирования с РЗМ.

(C) Siberian Federal University. All rights reserved

* Corresponding author E-mail address: j.a.gorbunov@gmail.com 
В группу редкоземельных металлов (РЗМ) входят 14 элементов - лантаноидов, а также скандий, иттрий и лантан. РЗМ остро востребованы в современных высокотехнологичных отраслях промышленности. Без них сегодня не мыслимо развитие современных ЭВМ, средств связи и коммуникаций, лазерной техники, оптических систем, низко температурных проводников, многих видов оборонной техники и т.п. Важную роль РЗМ могут сыграть и в развитии алюминиевых сплавов. В докладе выполнен обзор доступных результатов исследований, проведенных в этом направлении в нашей стране.

Систематические исследования влияния РЗМ на структуру и свойства алюминиевых сплавов начаты в 70-х годах в ИМЕТ АН СССР, ВИЛСе и ВИАМе. За рубежом аналогичные работы были организованы в исследовательском центре компании «Алкоа» (США). Работы специалистов ИМЕТ АН СССР показали, что алюминиевый угол диаграмм состояния РЗМ представляет собой эвтектическую систему алюминия с наиболее близким к нему по составу интерметаллическим соединением. Отличительной особенностью диаграмм состояния алюминия и РЗМ является малая взаимная растворимость в твердом состоянии. По данным различных исследований, растворимость не превышает 0,2-0,3 \%. М.Е. Дриц и Э.С. Каданер объяснили небольшую растворимость РЗМ в твердом алюминии неблагоприятностью основных факторов, определяющих образование твердых растворов, различием в системах упаковки атомов и атомных радиусов. Атомные радиусы РЗМ, сравнительно мало отличаясь друг от друга, значительно превосходят по величине атомный радиус алюминия.

Дальнейшие исследования, проведенные в ВИЛСе В.М. Федоровым с коллегами под руководством В.И. Добаткина, показали, что при относительно малых скоростях охлаждения при кристаллизации $(10 \mathrm{~K} / \mathrm{c})$ в сплавах алюминия, содержащих до 10 \% РЗМ, формируется грубая доэвтектическая структура с характерным расположением эвтектики по границам ветвей дендритов. При 10 \% РЗМ наблюдается грубая эвтектическая структура, а при 15 \% - заэвтектическая структура с первичными кристаллами интерметаллидов размером до 100 мкм и более.

При повышении скорости охлаждения сплавов эвтектическая структура трансформируется в доэвтектическую с одновременным уменьшением дендритного параметра и толщины прослоек интерметаллических фаз в эвтектике. В сплавах заэвтектического состава повышение скорости охлаждения приводит сначала к подавлению образования первичных кристаллов интерметаллидов, а затем к формированию доэвтектической структуры. Одновременно установлено, что изменения структуры сплавов алюминия с различными лантанидами очень схожи и количественные изменения структуры при переходе от одного элемента к другому сравнительно невелики.

Общие закономерности взаимодействия алюминия с РЗМ, установленные в вышеупомянутых работах советских ученых, позволили предложить ряд новых материалов и областей их эффективного практического применения. Одними из первых таких материалов стали рентгеноконтрастные сплавы для проверки качества сварных соединений и проводники электрического тока, предназначенные для повышенных температур эксплуатации.

\section{Рентгеноконтрастные сплавы}

При освоении производства ответственных конструкций из алюминиевых сплавов, получаемых с применением методов контактной и шовной сварки, задача неразрушающего контро-

$$
-637-
$$


ля сварных соединений была решена искусственным созданием химической неоднородности на границе литой зоны, выявляемой рентгеновским просвечиванием.

В.И. Добаткиным, В.М. Федоровым совместно с К.К. Билевым, Ю.И. Пономаревым, Б.В. Ильиным был проведен анализ химического состава ряда сплавов с применением металлов системы алюминий - РЗМ. Исходя из анализа структуры этих сплавов и их технологичности, предполагаемой при обработке давлением, были выбраны сплавы Al-Y и Al-Се при содержании иттрия и церия в диапазоне 11-13 \%. Для обеспечения коррозионной стойкости сварных соединений в состав сплавов исследуемых систем было дополнительно введено 0,7 \% хрома.

Детализация химического состава сплава и технологических параметров получения лент толщиной 0,1 мм была выполнена автором с коллегами с применением метода непосредственной прокатки гранул в горячем состоянии на стане «Дуо-200» и последующей раскатки полученной ленты в холодном состоянии до требуемой толщины на 6-валковом стане. Анализ микроструктур проката показал равномерное распределение по всему полю исследуемых зон дисперсных выделений интерметаллидных фаз $\mathrm{Al}_{4} \mathrm{Y}(\mathrm{Ce})$ и $\mathrm{Al}_{7} \mathrm{Cr}$. Плотность распределения и размеры этих выделений обеспечили сохранение нерекристаллизованной структуры сплавов на всех стадиях технологического передела и достаточно высокий уровень прочностных характеристик проката.

При исследовании точечных сварных соединений, выполненных через полученные ленты, установлено, что они характеризуются симметричным расположением литой зоны относительно контактной плоскости свариваемых листов, их хорошим проплавлением и отсутствием дефектов. Сварные точки независимо от условий испытаний отвечали предъявленным требованиям по разрушающей нагрузке, а наличие материала-свидетеля (MC) в нахлестке не ухудшало коррозионных свойств основного металла и сварного соединения.

При переходе к промышленному освоению производства МС лабораторией гранулированных материалов Красноярского института цветных металлов (КИЦМа) и Красноярским металлургическим заводом (КраМЗом) было разработано техническое задание ВНИИМЕТМАШу на проектирование стана для получения полосовой заготовки непосредственной прокаткой гранул в горячем состоянии. Однако принятие решения по этому вопросу затянулось. Поэтому в опытно-промышленных условиях КраМЗа была реализована технологическая схема, включающая экструдирование полос сечением 5х130 либо 6х160 мм из брикетированной заготовки с последующей ее прокаткой до требуемого размера. При этом экструдирование гранулированного сплава проводилось через форкамерный инструмент, со смоткой получаемой полосы в бухту для последующей холодной рулонной прокатки на стане «Кварто 500».

Исходя из экономических соображений, при освоении промышленной технологии вместо иттрия был применен цериевый мишметалл. Выполненные оценки показали равнозначность характеристик всей группы исследуемых сплавов при содержании РЗМ в количестве 1113 \%. Разработанный сплав получил марку 01415, на производство проката из него выпущены ТУ 1-808-014-77.

\section{Проводниковые сплавы}

В работах, проведенных В.И. Добаткиным, В.М. Федоровым, было показано, что добавки РЗМ практически не растворяются в алюминии при скоростях охлаждения до $10^{4} \mathrm{~K} / \mathrm{c}$. Благода- 
ря этому обеспечивается высокая электропроводность сплавов алюминия с РЗМ. Присутствующие в структуре сплавов интерметаллидные фазы РЗМ при указанных скоростях настолько диспергируются, что обеспечивают значительное повышение прочности и жаропрочности готовых полуфабрикатов.

Изучение технологических параметров обработки давлением таких материалов и производства проволоки из проводниковых сплавов системы «алюминий - РЗМ» было проведено в 1975-78 гг. на кафедре «Обработка металлов давлением» КИЦМа. В дальнейшем практические работы по промышленному освоению этих технологий были выполнены автором совместно с А.М. Штерензоном и И.Ф. Гилевичем в условиях КраМЗа.

В результате исследований, проведенных в ВИЛСе и опытном производстве КраМЗа, было показано, что наиболее универсальным для применения в качестве проводникового материала является сплав алюминия с 7 \% РЗМ, которому присвоена марка 01417. Этот сплав обладает высокой коррозионной стойкостью, хорошо сваривается, паяется и предназначен для изготовления бортовых проводов самолетов для длительной работы при температурах от -50 до $+250{ }^{\circ} \mathrm{C}$ взамен проводов с медной жилой. По данным ряда конструкторских бюро, применение сплава обеспечило снижение веса от 100 до 300 кг на одном изделии. На сплав получено авторское свидетельство СССР № 1549092, на химический состав сплава и поставку проволоки выпущены технические условия ТУ -806-661-82, ТУ -808-041-84. В соответствии с ними в отожженном состоянии механические свойства проволоки из сплава 01417 составляют: предел прочности не менее 157 МПа при относительном удлинении более $8 \%$, удельное электросопротивление менее 0,0320 мкОм $\cdot$ м.

Однако технология волочения проволоки малого диаметра (до 0,12-0,14 мм), необходимой для производства бортовых проводов, была недостаточно стабильна вследствие периодических обрывов заготовок из-за наличия внутренних дефектов, связанных с наследственным влиянием поверхностей гранул. Кроме того, возникали проблемы с ремонтом проводки из алюминиевых сплавов в условиях эксплуатации изделий. Поэтому провода из сплава 01417 на этом этапе широкого применения не получили.

Для получения из сплавов системы Al-P3М заготовок малого сечения с измельченной структурой, которые были бы свободны от недостатков материалов, получаемых методами гранульной технологий, автором предложено использование непрерывного литья заготовок малых сечений в электромагнитный кристаллизатор. Предложение было реализовано группой специалистов на опытной установке, разработанной в Красноярском политехническом институте [1]. Эффективное охлаждение расплава при кристаллизации обеспечило производство на этой установке непрерывно литых заготовок Ø12-15мм с уникальным сочетанием физикомеханических свойств.

В дальнейшем проф. С.Б. Сидельниковым и Д.С. Ворошиловым исследована технология получения проволоки Ø1,2-2мм, включающая обработку непрерывно литых заготовок на установке совмещенной прокатки прессования (СПП) и последующее холодное волочение на готовый размер. Испытания полученной проволоки показали, что она свободна от недостатков гранулированного предшественника и по совокупности технологических характеристик и свойств конечного продукта превосходит отечественный аналог, освоенный в свое время на КраМЗе.

$$
-639-
$$


Результаты исследований, недавно проведенных автором с коллегами, доказали возможность промышленного производства проволоки диаметром до 1,2 мм непосредственно из заготовки электромагнитного литья, минуя стадию деформационной обработки. Опытная партия такой проволоки была произведена в условиях ЛПЗ «Сегал» (г. Красноярск) и показала достаточно высокую технологичность материала при обработке на стане многократного волочения.

Эти эксперименты подтвердили, что плотная макроструктура заготовок и высокая степень измельчения составляющих структуры сплава, достигаемые при электромагнитном способе литья, обеспечивают эффективное использование преимуществ сплава 01417, заложенных его разработчиками на начальных стадиях исследований и промышленного производства. Поэтому проводниковые сплавы системы «алюминий - РЗМ» и в настоящее время могут рассматриваться как перспективные температуростойкие материалы для различных отраслей техники.

\section{Высокопрочные быстрозакристаллизованные сплавы}

Опытно-промышленные работы по освоению производства крупногабаритных полуфабрикатов из высокопрочных сплавов марок 01996, 01969, разработанных ВИЛСом и ВИАМом, показали нестабильность их структуры и трудность сохранения преимуществ быстрой кристаллизации при обработке больших масс металла. В первую очередь это было связано с высокими концентрациями ряда переходных металлов, введенных для усиления эффекта упрочнения, и недостаточной стойкостью образованных ими аномально пересыщенных твердых растворов. Поэтому было принято решение об исключении из состава сплавов хрома и марганца при одновременном снижении содержания цинка. При этом уменьшение суммарного содержания элементов антирекристаллизаторов было предложено компенсировать увеличением содержания циркония, а также введением таких элементов, как кобальт, никель и РЗМ.

Проведенные исследования показали, что предложенная комбинация тугоплавких металлов и введение РЗМ в высокопрочные сплавы способствуют повышению стабильности структуры материала при высокотемпературных технологических переделах. Происходит это как за счет повышения содержания в структуре стабильных высокодисперсных интерметаллических соединений, так и за счет образования сложных фаз, содержащих РЗМ и переходные металлы. Кроме того, введение РЗМ в высокопрочные сплавы уменьшает их окисляемость при литье и увеличивает стойкость полуфабрикатов против расслаивающей коррозии. При этом наличие перечисленных эффектов достигается уже при введении добавок РЗМ в количестве до 0,2 \%.

В результате серии исследований и опытно-промышленных экспериментов для изделий с длительной эксплуатацией предложен сплав, содержащий, кроме традиционных цинка, магния, меди и циркония, 0,3-0,7 \% кобальта, 0,1-0,4 \% никеля, 0,05- 0,2 \% церия или скандия, 0,002-0,05 бериллия. Сплав получил обозначение 01959 (авторское свидетельство СССР № 1450390). По сравнению со сплавом 01969 этот материал, легированный в числе других элементов цериевым мишметаллом, имел большую в среднем в 1,5-2 раза вязкость разрушения, в 1,5 раза выше удельную работу разрушения, на 15-20 \% меньшую чувствительность к концентраторам разрушения и отличную коррозионную стойкость. Сплав был паспортизован ВИАМ, на поставку прессованных полуфабрикатов утверждены ТУ 1-808-069-87. 
Для решения задачи по созданию супервысокопрочного алюминиевого сплава для изделий неответственного и разового назначения был предложен вариант комплексного легирования алюминия 7,5-10,5 \% цинка, 2,0-3,5 \% магния, 1,2-2,5 \% меди, а также цирконием, кобальтом, никелем и железом при одновременном введении до 1 \% РЗМ. Сплав получил марку 01979 (авторское свидетельство СССР № 1319596). Предложенный химический состав сплава в условиях опытно-промышленной обработки крупногабаритных заготовок обеспечил сохранение частично пересыщенного твердого раствора переходных металлов в алюминии до конечных операций технологического передела. Для достижения максимальных значений прочности в качестве конечной технологической операции применен режим одноступенчатого старения полуфабрикатов. Это обеспечило на экструдированных прутках диаметром от 30 до 10 мм предел прочности полуфабрикатов 840-860 МПа при относительном удлинении 9-11 \% и показателе расслаивающей коррозии (РСК), равном 4,5-5 баллам. На поставку прессованных полуфабрикатов из сплава 01979 утверждены ТУ 1-808-112-89.

По нашим сведениям, приведенные работы были одними из первых примеров применения РЗМ для легирования сплавов на основе алюминия. Однако, несмотря на уникальность достигнутых физико-механических характеристик вышеописанной группы материалов, производство полуфабрикатов из быстро закристаллизованных сплавов в нашей стране в прошедшие десятилетия практически прекратилось. Связано это не только с закрытостью информации в советское время и последующей остановкой оборонных производств. При распаде СССР остались за рубежом и утрачены месторождения циркония и многих других переходных металлов. Одновременно Россия прекратила или резко сократила добычу и производство большинства редких металлов. В числе других факторов свою роль сыграла высокая трудоемкость производства полуфабрикатов из быстро закристаллизованных сплавов и, соответственно, их высокая стоимость.

Практически параллельно с разработкой быстро закристаллизованных (гранулированных) сплавов отечественными учеными проводились исследования по применению РЗМ в рамках традиционных технологических процессов. Работы в этом направлении были акцентированы на особо эффективном воздействии на структуру алюминиевых сплавов такого элемента, как скандий. Скандий $(\mathrm{Sc})$ - химический элемент III группы периодической системы, имеющий

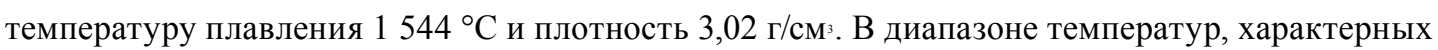
для работы с алюминиевыми сплавами, скандий имеет ГПУ решетку. Электронная конфигурация атома скандия аналогична иттрию и лантану и соответствует $3 \mathrm{~d} 4 \mathrm{~s}^{2}$. Растворимость скандия в алюминии составляет 0,3 \% масс. По физико-химическим свойствам скандий является аналогом иттрия и элементов-лантаноидов.

Большой комплекс работ по исследованию закономерностей влияния скандия на характеристики алюминия выполнен в ВИЛСе под руководством и при непосредственном участии проф. В.И. Елагина и В.В. Захарова. Установлено, что при легировании алюминия скандием имеют место характерные черты, свойственные легированию переходными металлами: малый температурный интервал кристаллизации твердых растворов, относительно низкая растворимость в алюминии, резкое снижение растворимости с понижением температуры. Результаты исследований показали, что введение скандия приводит к образованию в структуре алюминие-

$$
-641-
$$


вых сплавов когерентных с матрицей дисперсоидов $\mathrm{Al}_{3} \mathrm{Sc}$ и обеспечивает следующие преимущества:

- существенное измельчение зерна в литой заготовке и формирование недендритной структуры, связанное с сильнейшим модифицирующим действием первичных частиц $\mathrm{Al}_{3} \mathrm{Sc}$, что определяется изоморфностью их решетки решетке алюминия;

- уменьшение или полное подавление поверхностной рекристаллизации;

- повышение прочности полуфабрикатов на 20-25 \%;

- уменьшение или полное исключение образования трещин в сварных швах;

- увеличение прочности сварного соединения и повышение усталостной долговечности до $200 \%$.

Одним из важных моментов во всей технологической цепочке получения деформированных полуфабрикатов из алюминиевых сплавов, содержащих скандий, является образование пересыщенного твердого раствора скандия в алюминии при непрерывном литье слитков. Как отмечается в работах, опубликованных В.В. Захаровым в последние годы, это характерно даже для литья слитков диаметром до 800 мм. При правильно организованном процессе плавки и литья до 90 \% скандия входит в твердый раствор, а оставшиеся $10 \%$ выделяются в предкристаллизационный период в виде первичных частиц $\mathrm{Al}_{3} \mathrm{Sc}$, необходимых для модифицирования зеренной структуры слитков.

Твердый раствор скандия в алюминии весьма неустойчив и распадается уже при нагревах до $250{ }^{\circ} \mathrm{C}$ и выше. При этом средняя скорость распада твердого раствора в сплавах системы $\mathrm{Al}-\mathrm{Sc}$ примерно на четыре порядка выше, чем, например, в сплавах системы Al-Mn и на пять порядков, чем в сплавах Al-Zr. Поэтому при совместном присутствии в сплаве $\mathrm{Sc}$ и $\mathrm{Zr}$ в начальный период распадается твердый раствор скандия с образованием вторичных частиц $\mathrm{Al}_{3} \mathrm{Sc}$, а на поздних стадиях из твердого раствора диффундируют атомы циркония, которые растворяются в частицах $\mathrm{Al}_{3} \mathrm{Sc}$, трансформируя их в более сложную фазу $\mathrm{Al}_{3}\left(\mathrm{Sc}_{1-z} \ldots \mathrm{Zr}_{\mathrm{z}}\right)$. Распад твердого раствора приводит к сильному упрочнению матрицы алюминиевого сплава. При легировании двойного сплава Al-Sc цирконием величина и скорость упрочнения заметно возрастает.

По мнению исследователей Днепропетровского национального университета, вторичные частицы $\mathrm{Al}_{3} \mathrm{Sc}$, выпадающие из пересыщенного твердого раствора при нагреве, долго сохраняют когерентную связь с матрицей и очень медленно растут. Поэтому выделение вторичных частиц $\mathrm{Al}_{3} \mathrm{Sc}$ обусловливает наибольшее удельное упрочнение алюминиевой матрицы по сравнению с другими элементами периодической системы. Наличие дисперсных частиц $\mathrm{Al}_{3} \mathrm{Sc}$, когерентно связанных с матрицей, закрепляет дислокационные субграницы. Это способствует формированию в деформированных сплавах мелкой ячеистой дислокационной структуры, обладающей высокой термической стабильностью.

Скандий повышает температуру рекристаллизации деформированных полуфабрикатов заметно сильнее других элементов антирекристаллизаторов, таких как цирконий, марганец и хром, являющихся основными добавками в алюминиевых сплавах. Это связано с высокой дисперсностью продуктов распада твердого раствора скандия в алюминии. Добавка циркония, препятствующая коагуляции вторичных частиц, усиливает антирекристаллизационное действие скандия, повышая температуру рекристаллизации в некоторых сплавах вплоть до температуры солидуса. 
Полуфабрикаты, легированные скандием, имеют прочностные характеристики намного выше, чем полуфабрикаты из аналогичных сплавов, не содержащих скандий. В зависимости от назначения в ВИЛСе и ВИАМе разработана целая гамма таких конструкционных сплавов.

\section{Сплавы системы алюминий - магний - скандий (с содержанием магния от 1 до 6 \%)}

Наибольшее распространение в этой группе получил сплав 1570, превосходящий сплав АМг 6 по прочности различных полуфабрикатов на 40-80 МПа. Сплав 1570 характеризуется как лучший из высокопрочных свариваемых сплавов, обладая прочностью около 500 МПа при высокой пластичности и вязкости разрушения. Ресурсные характеристики сплава не уступают соответствующим характеристикам лучших высокоресурсных сплавов 1163 и 1161.

Листы из сплава 1570 обладают природной сверхпластичностью. Имея мелкозернистую структуру, они могут подвергаться большим пластическим деформациям без специальной подготовки. Это практически используется для получения заготовок деталей сложных форм при применении менее мощного (в 2-3 раза) прессового оборудования для их изготовления. Новый сплав, как и сплав АМг6, обладает достаточным сопротивлением коррозии во влажной атмосфере и в контакте с компонентами ракетного топлива. Важным достоинством сплава является способность сильно упрочняться при холодной деформации. Благодаря высокой свариваемости и хорошему сочетанию прочностных, пластических и коррозионных свойств, сплав 1570 нашел применение в ракетной технике, имеет определенные перспективы в самолетостроении и может быть использован для сварных рамных конструкций автомобиля.

На базе сплава 1570 разработан экономно легированный сплав 1575 , отличающийся пониженным содержанием скандия. Его предлагается использовать в виде экструдированных профилей в тяжело нагруженных строительных конструкциях для ферм, мостов, мачт, опор ЛЭП, в автомобильном и железнодорожном транспорте. Благотворно сказывается введение скандия во многие другие деформируемые сплавы, в частности в сплавы систем Al-Mg-Li и Al-Zn-Mg$\mathrm{Cu}$.

\section{Алюминиево-литиевые сплавы со скандием}

В промышленные сплавы системы Al-Mg-Li, являющиеся одними из приоритетных разработок $\mathrm{CCCP}^{1}$, скандий вводят с целью повышения прочности деформированных полуфабрикатов за счет сохранения нерекристаллизованной структуры и для улучшения свариваемости. К настоящему времени достаточно хорошо известны два таких сплава, разработанных под руководством И.Н. Фридляндера в ВИАМе, - 1421 и 1424. Преимущества этих сплавов очевидны: малая плотность (2,5 г/см³), высокий модуль упругости ( $E=77-80$ ГПа), достаточно высокая прочность при удовлетворительной пластичности, высокие характеристики трещиностойкости и в особенности циклической долговечности, хорошая коррозионная стойкость и удовлетворительная свариваемость. Это одни из самых перспективных сплавов для использования в авиакосмической промышленности, и альтернативу в этом плане им пока трудно найти.

Литий - стратегический металл для оборонной промышленности. До 20000 тонн этого металла производят США, Чили, Австралия, Китай и другие страны. По данным ФГУП «ВНИИМС», в России добыча лития прекращена. Заводы Красноярска и Новосибирска ввозят соединения лития из Чили и США.

$$
-643-
$$


Промышленные сплавы ВИАМ на основе системы $\mathrm{Al}-\mathrm{Cu}-\mathrm{Li}$, легированные скандием, например 1460 и 1464, относятся к числу наиболее прочных свариваемых алюминиевых сплавов. Временное сопротивление разрыву этих сплавов составляет до 600 МПа. Основное преимущество данных сплавов - способность работать при температуре жидкого водорода, что определяет их применение в топливных баках ракетно-космических комплексов.

\section{Высокопрочные сплавы со скандием}

Введение скандия в сплавы системы Al- $\mathrm{Zn}-\mathrm{Mg}-\mathrm{Cu}$ позволило нейтрализовать отрицательное влияние меди на коррозионные свойства полуфабрикатов (особенно в сварных соединениях). Скандий резко измельчает зерно в сварном шве и уменьшает склонность сплавов к образованию горячих трещин. С учетом этого в ВИЛСе разработан сверхпрочный сплав, предназначенный для замены сплава В96Ц в тяжело нагруженных элементах газовых центрифуг для разделения изотопов урана (патент RU № 2449037). Принципы легирования этого сплава во многом напоминают подходы, реализованные при создании быстро закристаллизованных сплавов 01959 и 01979. Они обеспечили достижение похожих эффектов на полуфабрикатах относительно небольших сечений, получаемых по традиционным технологиям.

Сотрудниками ВИАМа предложен сплав, содержащий кроме скандия серебро. Экструдированные полуфабрикаты из этого сплава, по данным патентной заявки, обладают прочностью более 800 МПа при относительном удлинении более 10 \% [2]. Аналогичное решение запатентовано и в США.

Опыт практического производства и применения показал, что удорожание полуфабрикатов из алюминиевых сплавов, легированных скандием, по сравнению со стоимостью полуфабрикатов, не содержащих его, составляет 60-80 \%. Такое удорожание компенсируется увеличением запаса прочности и существенным снижением веса конструкций летательных аппаратов. В итоге конструкции летательных аппаратов из сплава оказываются дешевле сопоставимых по целевой эффективности. Это доказывает, что, несмотря на высокую текущую стоимость сплавов со скандием, их можно рассматривать как весьма перспективные материалы, потенциально эффективные в различных отраслях промышленности.

В то же время РЗМ весьма востребованы и во многих других отраслях промышленности. Масштабы потребления РЗМ являются точным индикатором научно-технического развития страны. Нельзя говорить о «развитии нанотехнологий», если страна не производит и не потребляет редкие элементы. Подтверждением обоснованности этого утверждения служит развитие сплавов со скандием в ряде европейских стран и явное увеличение количества докладов по применению РЗМ на международных научно-практических конференциях, проводимых в последние десятилетия.

С учетом сложившихся обстоятельств Правительством Российской Федерации в рамках государственной программы «Развитие промышленности и повышение ее конкурентоспособности» утверждена в качестве составной части программа «Технологии редких и редкоземельных металлов». Целью программы является разработка, освоение и адаптация критических технологий производства редких и редкоземельных металлов для удовлетворения потребностей отечественного оборонно-промышленного комплекса, гражданских отраслей экономики и выхода на зарубежные рынки. Реализация программы предполагает полное покрытие к 
2020 г. российских потребностей за счет восстановления некогда крупнейшей в мире национальной редкоземельной отрасли, а также выход России на мировой рынок с продукцией высоких переделов.

Ситуация благоприятна и в том плане, что Россия располагает достаточно большими запасами скандиевого сырья. ОК «РУСАЛ» в марте 2013 г., рассматривая необходимость закрытия части нерентабельных цехов Богословского АЗ, приняла решение о создании на их площадях производства скандия с использованием красного шлама, накопленного при переработке бокситов. «Ростех» совместно с частными инвесторами планирует производство металлов цериевой группы из монацитовых песков, запасы которых накапливались еще с 30-х годов. Компания «Росатом» уже реализует создание аналогичных производств на базе переработки отходов урановых руд² и планирует создание совместного предприятия в Казахстане. Аналогичные возможности есть не только в Свердловской области, но и в Сибири, и в Карелии. В Восточной Сибири разведаны грандиозные запасы руд редкоземельных элементов. Содержание скандия в руде достигает 800 г на тонну. Запасы здесь так велики, что месторождение может стать главным мировым источником скандия. Поэтому развитие дальнейших исследований в части применения РЗМ, и в частности скандия, для создания новых материалов на основе алюминия является своевременной и актуальной задачей.

\section{Список литературы}

[1] Pervukhin M.V., Gorbunov Yu.A., Sergeev N.V., Timofeev V.N. // International Symposium on Heating by Electromagnetic Sources. Padua, June, 2004.

[2] Каблов Е.Н., Ткаченко Е.А., Антипов В.В., Вахромов Р.О. Пат. 2443793 РФ (2010) / Б. И. 2012. № 6 .

2 Горнорудный дивизион «Росатома» - холдинг АРМЗ — в 2013 г. запустил опытную установку по производству концентрата редкоземельных металлов из побочных продуктов обогащения урана на руднике Далур в Курганской области. Из этого концентрата гидрометаллургическим методом будут извлекать оксид скандия. 